\title{
Linking mean body size of pelagic Cladocera to environmental variables in Precambrian Shield lakes: A paleolimnological approach
}

\author{
Jennifer B. KOROSI*, Andrew M. PATERSON ${ }^{1)}$, Anna M. DESELLAS and John P. SMOL \\ Paleoecological Environmental Assessment and Research Laboratory (PEARL), Department of Biology, Queen's University, \\ Kingston, Ontario, K7L 3N6, Canada \\ ${ }^{1)}$ Ontario Ministry of the Environment, Dorset Environmental Science Centre, 1026 Bellwood Acres Road, P.O. Box 39, Dorset, ON, \\ P0A 1E0, Canada \\ *e-mail corresponding author: 3jk8@queensu.ca
}

\begin{abstract}
Daphnia and Bosmina fragments were identified and measured in the surface sediments of 42 lakes in the Muskoka-Haliburton region of Ontario, Canada, in an attempt to identify environmental factors that may influence cladoceran body size. Specifically, pecten length on Daphnia post-abdominal claws, antennule length on Bosmina headshields, and carapace and mucro lengths of Bosmina carapaces were measured. These measurements were then compared to limnological variables previously identified as possibly influencing cladoceran size, including dissolved organic carbon (DOC), total phosphorus (TP), pH, calcium (Ca), Chaoborus density, and fish presencelabsence. Cladoceran size displayed a linear relationship to TP, with larger Bosmina and Daphnia present in lakes with lower nutrient levels. We suspect that, as larger individuals are more efficient grazers, they may competitively exclude smaller individuals when nutrients are limiting in these lakes. Bosmina mucro length and cladoceran community size structure displayed a step response to DOC, with mean size significantly smaller when DOC concentrations were higher than 5.89 mg $L^{-1}$. Daphnia pecten length displayed a negative linear relationship to DOC above a concentration of $4.90 \mathrm{mg} \mathrm{l}^{-1}$. Reduced predation pressure from gape-limited macroinvertebrate predators, such as Chaoborus, may have influenced these relationships. DOC was also highly correlated to TP in these lakes, and size trends might be responding to the TP gradient rather than the DOC gradient. Mean cladoceran body size in acidic lakes $(\mathrm{pH}<6.0)$ was significantly smaller than mean body size in circumneutral lakes $(p H>6.0)$. There was no relationship between size structure and Ca concentrations, attributed to a narrow Ca gradient in these lakes. Predation effects were examined using limited Chaoborus density and fish presencelabsence data. Although there were no significant relationships between cladoceran size and Chaoborus density, some significant relationships between size variables and fish predation were identified. The sensitivity of size variables to certain environmental gradients suggests that size structure has the potential to be an effective paleolimnological tool.
\end{abstract}

Key words: Cladocera, size, paleolimnology, Precambrian Shield, abiotic and biotic variables, lakes

\section{INTRODUCTION}

Freshwater lakes are faced with multiple stressors due to human impacts on the environment (Schindler 2001; Yan et al. 2008a). Assessing the consequences of these stressors requires long-term data that, in the absence of detailed monitoring programs, may be obtained using paleolimnological techniques that examine the information preserved in lake sediment profiles (Smol 2008). While robust paleoenvironmental techniques have been developed for traditional algal indicators, the complex structure of aquatic ecosystems often requires the use of multiple proxies from various levels in the trophic web to ensure a more complete understanding of ecological interactions. The use of cladoceran indicators can provide a critical food web link to higher trophic levels. Although considerable progress has been made in tracking past algal trends, relatively little data currently exist for integrating historical changes in zooplankton.

Cladoceran microfossils are effective paleolimnological indicators due to their high ecological diversity, sensitivity to environmental change, and short genera- tion time that allows a rapid response to change (Korhola \& Rautio 2001). They have been used to track changes in climate (Korhola et al. 2005), acidification (Nilssen \& Sandoy 1990), fish predation (Amsinck et al. 2006; Davidson et al. 2006), phosphorus levels (Bos \& Cumming 2003), and salinity (Bos et al. 1999). Typically, paleolimnological inferences are based on cladoceran species assemblages. However, cladoceran size structure is also a potentially sensitive measure that may be responsive to changes in limnological conditions (Gamble et al. 2006). Mean cladoceran size, a community metric, has been used mainly to infer fish and invertebrate predation regimes (Brooks \& Dodson 1965; Sweetman \& Finney 2003), but relationships between size and abiotic factors have also been documented. For example, Manca and Comoli (2004) found that maximum body size of Daphnia is dependent on summer temperatures and the duration of the ice-free period, with reductions in temperature linked to larger size at maturity (Moore et al. 1996). In addition, lower phosphorus levels favour large-bodied species because they have a lower nutrient limiting threshold compared to 
small-bodied species (Gliwicz 1990). Given the relative ease of measuring Cladocera, these size-based approaches could potentially compliment community assemblage approaches to provide a more complete reconstruction of past environmental conditions. To date, few comprehensive paleolimnological studies on cladoceran body size have been conducted.

In this paper we explore relationships between the size of sedimentary Cladocera preserved in the surface layer of sediment of 42 lakes in south-central Ontario, Canada, and measured chemical ( $\mathrm{pH}$, total phosphorus, dissolved organic carbon, calcium) and biological (fish presence/absence and Chaoborus density) variables. We explore changes in cladoceran size at a genus or grouplevel, and at a community level. These predictor variables we chose were based on previously identified factors that are important determinants of cladoceran size (Yan et al. 2008b). Based on the results of previous limnological studies, we hypothesized that the mean size of cladoceran groups, and the community index, will be higher under low total phosphorus (TP; Brooks \& Dodson 1965; Burns \& Rigler 1967; Gliwicz 1990), and lower with declining dissolved organic carbon (DOC; Yan et al. 2008b). Calcium (Ca) is a key structural component of cladoceran carapaces, in particular Daphnia (Jeziorski \& Yan 2006), and, as a result, low Ca concentrations in lakewater could potentially display lower mean cladoceran body sizes. We also predicted that cladocerans will be larger, on average, in lakes with high Chaoborus density, and smaller in lakes where fish contribute to the majority of predation (Brooks \& Dodson 1965; Nilssen \& Sandoy 1990). The results of studies such as this one can potentially help improve our understanding of the ecological optima and long-term fluctuations in cladoceran communities, and confirm the validity of using size-based approaches in the paleolimnological study of Cladocera.

\section{MATERIAL AND METHODS}

\subsection{Study site description}

The 42 study lakes are located in south-central Ontario, in the Muskoka-Haliburton region of the southern Canadian Shield (Fig. 1). Underlain by Precambrian granitic bedrock, soils in this region are generally shallow, acidic, and low in nutrients (Chapman \& Putnam 1984). Thin soil and cool climate make this region unsuitable for agricultural development, and instead it is a popular destination for recreation and cottage-use. As a result, many catchments are characterized by shoreline development with surrounding deciduous and coniferous forests.

Lakes in this region have been subjected to a variety of anthropogenic stressors (Neary et al. 1990; Hall \& Smol 1996). Industrial emissions deposit acid and metals over the region (Neary et al. 1990; Yan et al. 2008a), although the majority of lakes in this study had a $\mathrm{pH}$

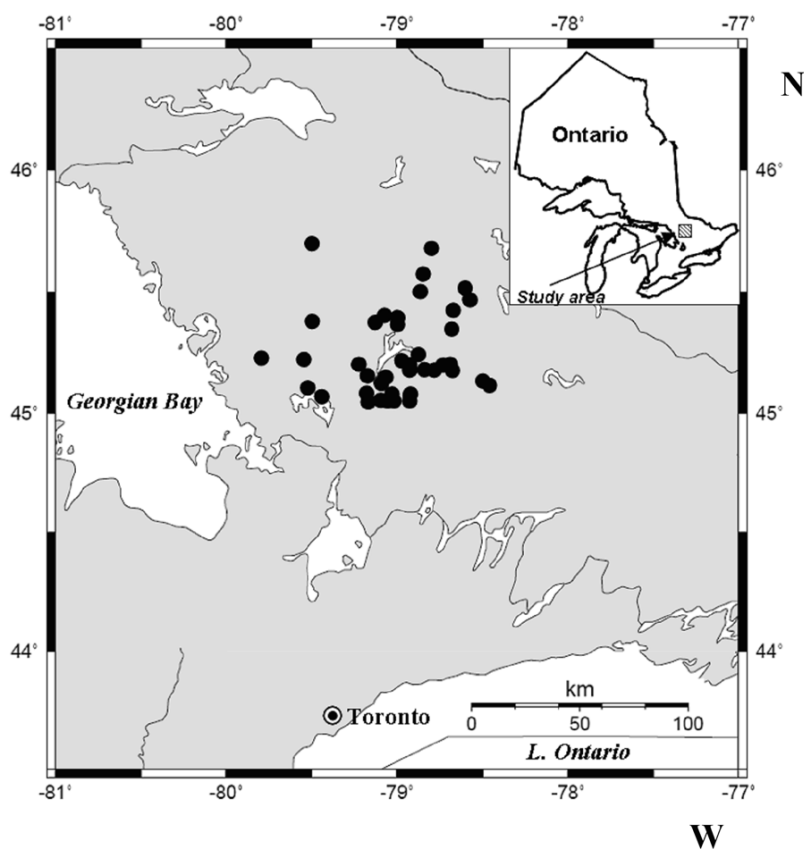

Fig. 1. Map showing the location of the 42 study lakes in the Muskoka-Haliburton region of south-central Ontario, Canada.

higher than 6.0 (Palmer \& Yan, York University, impublished data). There has been a marked increase in colonial scaled chrysophyte algae in lakes, which could be linked to taste and odour problems (Paterson et al. 2004). In addition, total phosphorus (TP) levels have been decreasing in several lakes despite increased shoreline and cottage development (Hall \& Smol 1996; Dillon \& Molot 2005). Although the mechanisms behind TP decline are complex, it has been suggested that reduced $\mathrm{P}$ loading from watersheds due to acidification processes or reforestation might be partially responsible (Hall \& Smol 1996). Calcium (Ca) levels are also decreasing (Keller et al. 2001; Watmough et al. 2003), and this is of concern because Cladocera, particularly Daphnia, have high $\mathrm{Ca}$ requirements for growth and development (Jeziorski \& Yan 2006). Acid rain deposition caused $\mathrm{Ca}$ mobilization and export to lakes to increase in the latter half of the century (Cosby et al. 1985), resulting in excessive losses of Ca from watershed soils. Since the rate of Ca replenishment in southern Shield lakes from soil leaching is slow (Driscoll et al. 2001), Ca decline is expected until a new steady state is reached (Watmough et al. 2003).

Invasive species introductions represent an additional stressor. For example, Bythotrephes longimanus, an invasive predatory cladoceran species, has been documented in 8 of the 42 study lakes, including Devine, Harp, Kimball, Leonard, Nunikani, Red Pine, Sherborne, and Young lakes (Palmer \& Yan, York University, unpublished data). Similarly, an increase in subfossil Eubosmina mucro length was documented in 
Lake Maggiore, Italy, in response to a higher abundance of Bythotrephes and other invertebrate predators (Manca et al. 2007).

\subsection{Field methods}

Replicate sediment cores were taken from the deepest basin of each of the 42 study lakes in the autumns of 2004 or 2005 (DeSellas et al. 2008). A Glew (1989) gravity corer and a miniature Glew (1991) gravity corer were used to collect sediment cores, and a Glew (1988) vertical extruder was used to extract the top 1-cm of sediment from each core (DeSellas et al. 2008). The sediment was stored at the Paleoecological Environmental
Assessment and Research Laboratory (PEARL) at Queen's University in Kingston, Ontario and stored at 4 ${ }^{\circ} \mathrm{C}$ (DeSellas et al. 2008). Chemical and physical data (Tab. 1) for the study lakes were collected during the ice-free seasons of 2004 and 2005 using standard Ontario Ministry of the Environment methods (Palmer et al. impublished data). Lakes were sampled for Chaoborus abundance in the mid-1980's over several years (Wissel et al. 2003; Tab. 1). A fish presence/ absence matrix, developed for our study lakes using unpublished data provided by the Ontario Ministry of Natural Resources, was used as a measure of fish predation (DeSellas et al. 2008). Briefly, fish taxa that were not present in three or more lakes were removed from

Tab. 1. Chemical (Palmer \& Yan, York University impublished data) and biological variables (Wissel et al. 2003; Fish PCA, DeSellas et al. 2008) for the 42 study lakes collected in 2004 or 2005. (* lakes with the invasive predatory Cladocera Bythotrephes longimanus).

\begin{tabular}{|c|c|c|c|c|c|c|c|c|}
\hline Lake & $\begin{array}{c}\mathrm{TP} \\
\left(\mu \mathrm{g} \mathrm{L}^{-1}\right)\end{array}$ & $\begin{array}{c}\text { DOC } \\
\left(\mathrm{mg} \mathrm{L}^{-1}\right)\end{array}$ & $\begin{array}{c}\mathrm{Ca} \\
\left(\mathrm{mg} \mathrm{L}^{-1}\right)\end{array}$ & $\mathrm{pH}$ & $\begin{array}{c}\text { Chaoborus } \\
\text { density } \\
\left(\text { No. } \mathrm{m}^{-3}\right)\end{array}$ & Fish PCA 1 & Fish PCA 2 & Fish PCA 3 \\
\hline Axe & 12.0 & 10.3 & 1.5 & 5.2 & 31.2 & 0.7 & 2.6 & 0.8 \\
\hline Basshaunt & 6.1 & 4.7 & 3.9 & 6.6 & 4.2 & 0.6 & 1.8 & 2.2 \\
\hline Bigwind & 6.0 & 3.8 & 2.2 & 6.4 & 7.1 & 1.1 & 0.9 & 2.5 \\
\hline Blue Chalk & 7.0 & 2.4 & 2.4 & 6.8 & 89.9 & 2.6 & 0.4 & 2.4 \\
\hline Bonnechere & 5.9 & 4.3 & 1.8 & 6.1 & 0.9 & 1.4 & 1.6 & 1.5 \\
\hline Buck & 6.5 & 3.3 & 2.6 & 6.4 & 104.6 & 0.5 & 2.7 & 2.2 \\
\hline Chub & 9.6 & 5.8 & 1.9 & 5.8 & 104.6 & 0 & 1.9 & 0.7 \\
\hline Cinder E & 12.3 & 6.8 & 1.9 & 5.7 & 126.2 & 2.6 & 2.4 & 0.3 \\
\hline Cinder W & 13.4 & 6.5 & 1.9 & 5.9 & 23.2 & 2.6 & 2.4 & 0.3 \\
\hline Cradle & 6.5 & 2.2 & 1.5 & 6.2 & 7.4 & 1.9 & 3.7 & 1.8 \\
\hline Crosson & 9.5 & 7.4 & 1.8 & 5.8 & 35.9 & 1.0 & 1.1 & 2.2 \\
\hline Crown & 4.8 & 2.8 & 1.7 & 6.4 & 66.3 & 1.3 & 0.4 & 0.4 \\
\hline Delano & 8.3 & 6.5 & 2.2 & 6.1 & - & 2.7 & 2.3 & 2.1 \\
\hline Devine* & 11.5 & 6.4 & 2.4 & 6.2 & 52.4 & 1.4 & 1.6 & 1.5 \\
\hline Dickie & 9.6 & 5.9 & 3.2 & 6.0 & - & 0.7 & 0.9 & 1.1 \\
\hline Hamer & 12.2 & 9.0 & 2.7 & 6.0 & 1.5 & 0.1 & 2.0 & 0.9 \\
\hline Harp* & 6.3 & 4.2 & 2.8 & 6.4 & 32.8 & 0.4 & 2.9 & 2.9 \\
\hline Healey & 10.4 & 6.5 & 2.7 & 6.4 & 0.3 & 1.7 & 1.0 & 0.4 \\
\hline Heney & 6.2 & 3.8 & 1.6 & 5.9 & 0.6 & 1.2 & 0.8 & 0 \\
\hline Kimball* & 3.6 & 3.1 & 2.0 & 6.2 & 78.6 & 1.6 & 0 & 3.5 \\
\hline Leech & 7.9 & 5.3 & 3.1 & 6.2 & 1.1 & 0.1 & 0.7 & 1.1 \\
\hline Leonard* & 6.9 & 4.2 & 2.4 & 6.5 & 28.1 & 0.5 & 1.4 & 0.2 \\
\hline Little Clear & 7.0 & 2.9 & 3.4 & 6.6 & 114.6 & 2.0 & 1.6 & 0.9 \\
\hline Maggie & 4.5 & 2.4 & 1.3 & 5.8 & 0 & 1.4 & 1.6 & 1.5 \\
\hline McKay & 8.9 & 5.5 & 3.1 & 6.6 & 101.6 & 0.6 & 0.6 & 0.6 \\
\hline Moot & 13.0 & 6.8 & 2.1 & 5.9 & 109.4 & 0.3 & 1.6 & 1.1 \\
\hline Nunikani* & 4.6 & 3.7 & 2.2 & 6.4 & 129.0 & 0.5 & 0.2 & 1.7 \\
\hline Pearceley & 4.8 & 2.0 & 1.0 & 5.5 & 38.4 & 2.2 & 3.5 & 2.4 \\
\hline Pincher & 4.5 & 2.5 & 1.2 & 5.8 & 51.7 & 1.0 & 3.8 & 1.5 \\
\hline Plastic & 6.3 & 2.4 & 1.5 & 5.6 & 59.5 & 1.4 & 1.0 & 0.8 \\
\hline Poker E & 10.6 & 6.8 & 1.8 & 6.2 & 19.6 & 2.9 & 1.2 & 0 \\
\hline Poker W & 10.3 & 6.3 & 1.9 & 6.5 & 55.9 & 3.2 & 1.5 & 0.1 \\
\hline Red Chalk E & 6.1 & 3.2 & 2.3 & 6.5 & 0.3 & 3.3 & 1.7 & 2.0 \\
\hline Red Chalk M & 11.1 & 3.4 & 2.2 & 5.9 & - & 3.4 & 1.5 & 2.5 \\
\hline RedPine* & 4.3 & 3.3 & 2.3 & 6.2 & - & 0.5 & 0.5 & 2.3 \\
\hline Saw & 14.6 & 8.3 & 2.5 & 6.1 & 0.2 & 0.9 & 3.1 & 1.3 \\
\hline Sherborne* & 4.4 & 3.4 & 1.9 & 6.3 & 2.6 & 2.3 & 0.1 & 1.9 \\
\hline Smoke & 4.9 & 3.7 & 2.3 & 6.6 & 2.8 & 1.1 & 0.4 & 3.3 \\
\hline Solitaire & 7.6 & 2.4 & 2.5 & 6.5 & 111.8 & 1.1 & 2.2 & 3.3 \\
\hline Timberwolf & 5.9 & 4.7 & 1.9 & 6.3 & 171.6 & 2.8 & 1.2 & 2.8 \\
\hline Walker & 5.2 & 4.1 & 3.2 & 6.8 & - & 0.6 & 1.4 & 1.2 \\
\hline Young* & 7.9 & 3.4 & 2.6 & 6.9 & - & 0.3 & 2.4 & 2.5 \\
\hline
\end{tabular}


the dataset. Principal components analysis (PCA) was performed on the remaining presence/absence matrix, and the resulting PCA axes 1, 2, and 3 scores were included as predictor variables of cladoceran size structure in the dataset (Tab. 1).

\subsection{Laboratory methods}

The top 1-cm of sediment from one core for each lake was analysed as a representative sample of recent cladoceran assemblages within each lake. Microscope slides for each lake were prepared, with ten or more replicates for each, using the techniques outlined in Korhola and Rautio (2001). Sediments were mixed with $10 \% \mathrm{KOH}$ and heated for 30 minutes, after which the mixture was poured onto a $37 \mu \mathrm{m}$ sieve and washed with de-ionized water. Ethanol was added to prevent fungal growth, and safranin-glycerin solution was used to colour the cladoceran fragments. Slides were prepared using glycerin jelly.

Fossilized fragments (carapaces, headshields, and postabdominal claws) of daphniids and bosminiids were then identified. Bosminiids were separated into Bosmina spp. or Eubosmina spp. depending on the location of the lateral headpore (Taylor et al. 2002; Witty 2004). Daphniids were placed into one of three major groupings based on the morphology of the middle pecten on the postabdominal claw (Witty 2004).
The Daphnia pulex complex (D. pulex, D. pulicaria, $D$. catawba, and D. minnehaha) had a stout middle pecten, the Daphnia ambigua complex (D. ambigua, D. dentifera, D. mendotae, D. dubia, and D. longiremis) had a uniform middle pecten, and the $D$. retrocurva group ( $D$. parvula and $D$. retrocurva) had a long middle pecten. The $D$. retrocurva group was rare in these lakes, and only the D. ambigua and D. pulex groups were included in statistical analyses.

In all, 50 carapaces and headshields (Bosminidae), as well as 50 postabdominal claws (Daphnidae), were identified from each lake using a Leica DMRB light microscope with bright field optics (20-40x objective, $15 \mathrm{x}$ ocular lens) equipped with a digital camera. Fragments were measured using Northern Eclipse image analysis software, version 50 (Empix Imaging Inc.). The headshield antennule length (AL), carapace length (CL), and mucro length (ML) were measured on Bosmina remains (Figs 2a, b). Bosmina CL represented general body size for Daphnia post-abdominal claw length with carapace length, and $\mathrm{AL}$ and $\mathrm{ML}$ were selected because they have been shown to respond to changes in predation regimes (Brooks \& Dodson 1965). Since a strong correlation exists for Daphnia postabdominal claw lenght with carapace lenght (Hrbáček 1969) and total body length (Manca \& Comoli 1996), pecten length (PL) of Daphnia postabdominal claws was also measured (Fig. 2c).

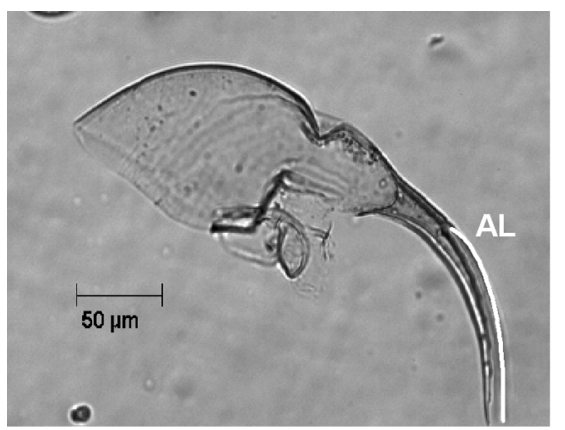

a)

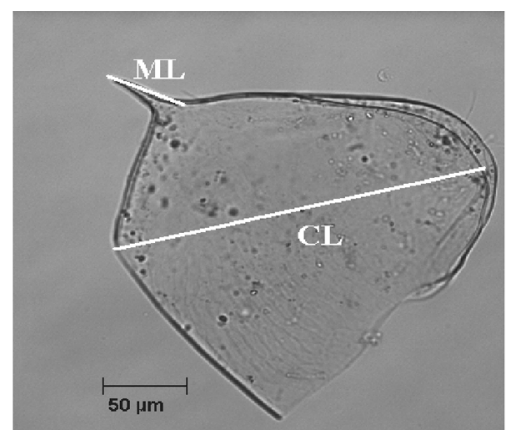

b)

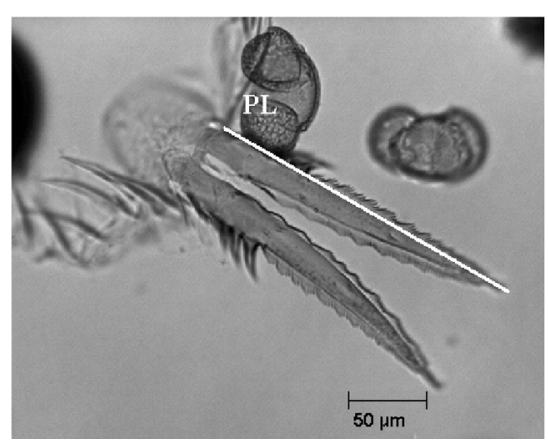

c)

Fig. 2. Photographs showing the location of the measurements for a) Bosmina antennule length (AL); b) Bosmina carapace (CL) and mucro (ML) lengths; c) Daphnia pecten length (PL). Photographs were taken by J. Korosi using surface sediments from the southcentral Ontario study lakes. 


\subsection{Statistical analysis}

Six size means were calculated for each lake (mean Eubosmina AL, mean Bosmina AL, CL, and ML, and mean $D$. pulex and D. ambigua PL). Principal components analysis (PCA), an indirect ordination technique, was performed using these size means to generate a single value representing the mean community size for each lake (PCA axis 1). The resulting 'community size index' was then added to the dataset and included in subsequent analyses.

Tests for normality were performed on both limnological and cladoceran size data to determine if datasets were normally distributed. Based on the results of these tests, TP and DOC were $\log (\mathrm{x})$-transformed. Least squares, linear regressions were run to reveal possible correlations between size means and limnological variables (TP, DOC, pH, Ca, Chaoborus density, fish PCA axes 1, 2 , and 3). Results of this analysis revealed possible break-point values for size with certain variables, suggesting segmented linear regressions might be more appropriate. Thus, a posteriori, we used segmented linear regressions with break-points to separate data into two groups according to the value of the limnological variable in question (Oosterbaan et al. 1990). Specifically, we determined whether the consideration of a threshold size response along environmental gradients was more appropriate (i.e., explained more variance) than a linear response. This type of analysis identifies threshold values (minimum value of a limnological variable that must be present in order for a size response to occur) that can be useful in monitoring studies and lake management.

The SegRegW computer program (Windows version 1.1.0.0; developed by Roland Oosterbaan) was used to detect environmental thresholds for cladoceran size in the data (http://www.waterlog.info/segreg.htm). The program was used to test for a segmented regression with one break-point, using one independent variable (e.g., $\mathrm{pH}$ ) and one response variable (e.g., Bosmina carapace length). The program selected one of seven function types (0-6) that maximized the coefficient of explanation $\left(\mathrm{R}^{2}\right)$, and passed a test of significance based on an alpha value of 0.05 (Oosterbaan et al. 1990; see Tab. 2 for a description of function types). The program also generated $90 \%$ confidence intervals and an ANOVA table.

\section{RESULTS}

Cladoceran remains in the surface sediments of the study lakes were well preserved and intact, allowing accurate measurements to be taken. Differences in size

Tab. 2. Results of SegRegW for cladoceran size with chemical and biological variables. A Type 0 function is one horizontal line (no relationship), Type 1 is a linear regression, Type 3 is a horizontal line followed by a sloping line, Type 4 a sloping line followed by a horizontal line, and Type 5 is a step function, with two horizontal lines with significantly different means. Bolded values are statistically significant $(p=0.05) . \mathrm{BP}=$ break-point, $\mathrm{TP}=$ total phosphorus, $\mathrm{DOC}=$ dissolved organic carbon, $\mathrm{Ca}=\mathrm{calcium}$.

\begin{tabular}{|c|c|c|c|c|c|c|c|c|c|c|c|c|}
\hline \multirow[t]{2}{*}{ a) } & \multicolumn{3}{|c|}{$\mathrm{TP}$} & \multicolumn{3}{|c|}{ DOC } & \multicolumn{3}{|c|}{$\mathrm{pH}$} & \multicolumn{3}{|c|}{$\mathrm{Ca}$} \\
\hline & Type & $\mathrm{BP}$ & $\mathrm{R}^{2}$ & Type & $\mathrm{BP}$ & $\mathrm{R}^{2}$ & Type & $\mathrm{BP}$ & $\mathrm{R}^{2}$ & Type & BP & $\mathrm{R}^{2}$ \\
\hline Bosmina CL & 3 & 0.8 & 0.3 & 5 & 0.8 & 0.2 & 4 & 6.1 & 0.2 & 0 & - & - \\
\hline Bosmina $\mathrm{ML}$ & 3 & 0.9 & 0.4 & 5 & 0.8 & 0.5 & 5 & 6.1 & 0.1 & 0 & - & - \\
\hline Bosmina AL & 4 & 0.8 & 0.2 & 5 & 0.6 & 0.1 & 0 & - & - & 0 & - & - \\
\hline Eubosmina $\mathrm{AL}$ & 1 & - & 0.1 & 5 & 0.7 & 0.2 & 0 & - & - & 0 & - & - \\
\hline D. ambigua complex PL & 1 & - & 0.4 & 3 & 0.7 & 0.5 & 5 & 6 & 0.2 & 0 & - & - \\
\hline D. pulex complex PL & 0 & - & - & 0 & - & - & 0 & - & - & 0 & - & - \\
\hline Community index & 5 & 1 & 0.2 & 5 & 0.8 & 0.2 & 0 & - & - & 0 & - & - \\
\hline
\end{tabular}

b)

\begin{tabular}{|c|c|c|c|c|c|c|c|c|c|c|c|}
\hline \multicolumn{3}{|c|}{ Chaoborus density } & \multicolumn{3}{|c|}{ Fish PCA axis 1} & \multicolumn{3}{|c|}{ Fish PCA axis 2} & \multicolumn{3}{|c|}{ Fish PCA axis 3} \\
\hline Type & $\mathrm{BP}$ & $\mathrm{R}^{2}$ & Type & $\mathrm{BP}$ & $\mathrm{R}^{2}$ & Type & BP & $\mathrm{R}^{2}$ & Type & $\mathrm{BP}$ & $\mathrm{R}^{2}$ \\
\hline 0 & - & - & 0 & - & - & 4 & 1.6 & 0.1 & 1 & - & 0.1 \\
\hline 0 & - & - & 0 & - & - & 0 & - & - & 1 & - & 0.2 \\
\hline 0 & - & - & 0 & - & - & 0 & - & - & 5 & 1.1 & 0.3 \\
\hline 0 & - & - & 0 & - & - & 0 & - & - & 1 & - & 0.4 \\
\hline 0 & - & - & 5 & 0.4 & 0.3 & 0 & - & - & 0 & - & - \\
\hline 0 & - & - & 0 & - & - & 0 & - & - & 0 & - & - \\
\hline 0 & - & - & 0 & - & - & 0 & - & - & 4 & 1 & 0.4 \\
\hline
\end{tabular}


means and standard deviations were displayed across lake environmental gradients. In all, size trends were analyzed for eight chemical and biological variables: total phosphorus (TP), dissolved organic carbon (DOC), $\mathrm{pH}$, calcium (Ca), Chaoborus density, and fish PCA axes 1,2 , and 3 .

Results from the least squares, linear regressions for TP revealed significant negative correlations $(\mathrm{p} \leq 0.05)$ with Bosmina carapace and mucro length $\left(\mathrm{R}^{2}=0.15\right.$, 0.36 respectively), Eubosmina antennule length $\left(\mathrm{R}^{2}=\right.$ $0.14)$, Daphnia ambigua complex pecten length $\left(\mathrm{R}^{2}=\right.$ 0.39 ), and the pelagic cladoceran community size index $\left(\mathrm{R}^{2}=0.13\right)$. SegRegW analysis confirmed that Eubosmina antennule length (Fig. 3d) and D. ambigua pecten length (Fig. 3b) were best described by a linear function of decreasing length with increasing TP concentrations (Tabs 2a and 3a). Significant break-points were identified for Bosmina mucro length and the community index $\left(\mathrm{BP}=7.94\right.$ and $9.55 \mu \mathrm{g} \mathrm{L}^{-1}$ respectively; Tabs 2a and 3a). Bosmina mucro length displayed a Type 3 relationship with TP, with a horizontal line followed by a sloping line when TP was higher than the break-point value (Fig. 3a). The community size index with TP was a true step function (Type $5, \mathrm{BP}=9.55 \mu \mathrm{g}$ $\mathrm{L}^{-1}$ ), with two horizontal lines on either side of a breakpoint with significantly different means (Fig. 3c). Overall, individual size trends displayed a negative linear relationship with TP, with smaller remains found in lakes with higher TP levels. No statistically significant trends were observed with Bosmina antennule length and Daphnia pulex pecten length.

Significant linear relationships were observed for DOC with Bosmina mucro length, Eubosmina antennule length, and D. ambigua pecten length $\left(\mathrm{R}^{2}=0.26,0.11\right.$, 0.43 , respectively), however results of the segmented linear regressions suggested that some size trends were better described when break-points were introduced (Tabs 2a and 3a). A Type 5 function was determined for Bosmina mucro (Fig. 4c) length and the community index (Fig. 4b), while a Type 3 function best described $D$. ambigua pecten trends (Fig. 4a). No trends were observed, linear or segmented, with $D$. pulex pecten lengths (Tab. 3a). The introduction of a break-point (BP $=0.69$ or $4.90 \mathrm{mg} \mathrm{L}^{-1} \mathrm{DOC}$ ) in the D. ambigua linear
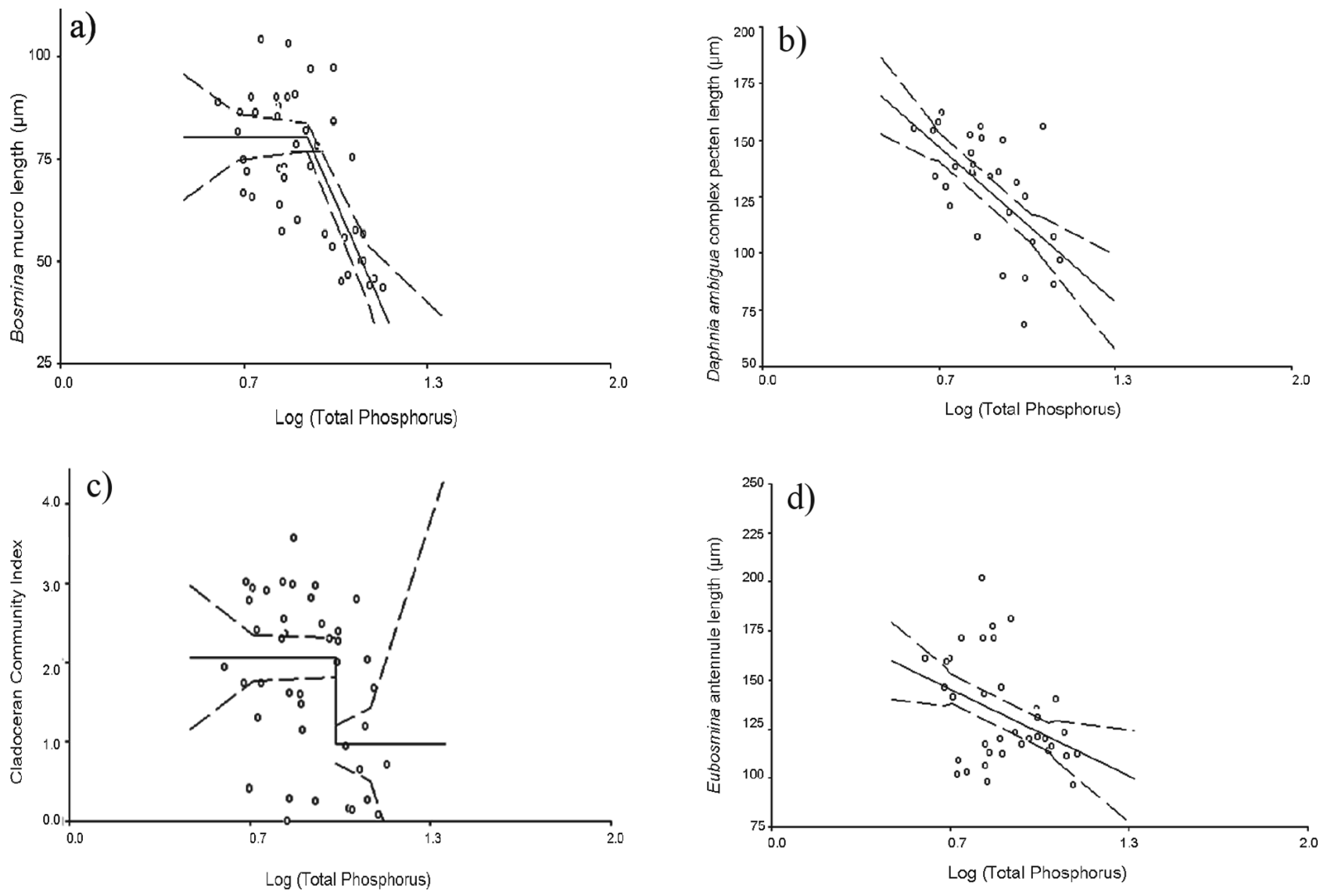

Fig. 3. Graph showing a) a Type-3 relationship between Bosmina mucro length and logTP; b) a linear relationship between Daphnia ambigua complex pecten length and $\log \mathrm{TP}$; c) a Type-5 step relationship between the cladoceran community index and logTP; d) a linear relationship between Eubosmina antennule length and $\log \mathrm{TP}$. The $90 \%$ confidence belts are shown. 
Tab. 3. A comparison of the results from the linear and segmented regression analyses for chemical and biological variables. RL and $\mathrm{PL}=\mathrm{R}^{2}$ and $p$-value for linear regression, $\mathrm{RS}$ and $\mathrm{PS}=\mathrm{R}^{2}$ and $p$-value for segmented regression. Bolded values are statistically significant $(p=0.05)$.

\begin{tabular}{|c|c|c|c|c|c|c|c|c|c|c|c|c|c|c|c|c|}
\hline \multirow[t]{2}{*}{ a) } & \multicolumn{4}{|c|}{$\mathrm{TP}$} & \multicolumn{4}{|c|}{ DOC } & \multicolumn{4}{|c|}{$\mathrm{pH}$} & \multicolumn{4}{|c|}{$\mathrm{Ca}$} \\
\hline & $\mathrm{R}_{\mathrm{L}}$ & $\mathrm{P}_{\mathrm{L}}$ & $\mathrm{R}_{\mathrm{S}}$ & $\mathrm{P}_{\mathrm{S}}$ & $\mathrm{R}_{\mathrm{L}}$ & $\mathrm{P}_{\mathrm{L}}$ & $\mathrm{R}_{\mathrm{S}}$ & $\mathrm{P}_{\mathrm{S}}$ & $\mathrm{R}_{\mathrm{L}}$ & $\mathrm{P}_{\mathrm{L}}$ & $\mathrm{R}_{\mathrm{S}}$ & $\mathrm{P}_{\mathrm{S}}$ & $\mathrm{R}_{\mathrm{L}}$ & $\mathrm{P}_{\mathrm{L}}$ & $\mathrm{R}_{\mathrm{S}}$ & $\mathrm{P}_{\mathrm{S}}$ \\
\hline Bosmina CL & 0.15 & 0.01 & 0.34 & 0.47 & 0.08 & 0.07 & 0.16 & 0.06 & 0.01 & 0.23 & 0.15 & 0.03 & 0 & 0.86 & - & - \\
\hline Bosmina $\mathrm{ML}$ & 0.36 & $<0.01$ & 0.38 & 0.01 & 0.26 & $<0.01$ & 0.53 & $<0.01$ & 0.09 & 0.06 & 0.13 & 0.19 & 0.01 & 0.48 & - & - \\
\hline Bosmina AL & 0.06 & 0.14 & 0.17 & 0.16 & 0.04 & 0.21 & 0.11 & 0.09 & 0 & 0.61 & - & - & 0 & 0.64 & - & - \\
\hline Eubosmina $\mathrm{AL}$ & 0.14 & 0.02 & 0.14 & 0.02 & 0.11 & 0.04 & 0.17 & 0.16 & 0.02 & 0.40 & - & - & 0.03 & 0.30 & - & - \\
\hline D. ambigua $\mathrm{PL}$ & 0.39 & $<0.01$ & 0.39 & $<0.001$ & 0.43 & $<0.01$ & 0.52 & 0.03 & 0.03 & 0.34 & 0.20 & 0.02 & 0 & 0.30 & - & - \\
\hline D. pulex $\mathrm{PL}$ & 0.05 & 0.25 & - & - & 0 & 0.85 & - & - & 0.03 & 0.38 & - & - & 0.03 & 0.36 & - & - \\
\hline Comm. index & 0.13 & 0.01 & 0.23 & 0.04 & 0.08 & 0.06 & 0.22 & 0.02 & 0.02 & 0.42 & - & - & 0.01 & 0.49 & - & - \\
\hline
\end{tabular}

b) Fish PCA axis 1

Fish PCA axis 2

Fish PCA axis 3

\begin{tabular}{|c|c|c|c|c|c|c|c|c|c|c|c|c|c|c|c|c|}
\hline & & & & & & & & & & \\
\hline & $\mathrm{R}_{\mathrm{L}}$ & $\mathrm{P}_{\mathrm{L}}$ & $\mathrm{R}_{\mathrm{S}}$ & $\mathrm{P}_{\mathrm{S}}$ & $\mathrm{R}_{\mathrm{L}}$ & $\mathrm{P}_{\mathrm{L}}$ & $\mathrm{R}_{\mathrm{S}}$ & $\mathrm{P}_{\mathrm{S}}$ & $\mathrm{R}_{\mathrm{L}}$ & $P_{L}$ & $\mathrm{R}_{\mathrm{S}}$ & $\mathrm{P}_{\mathrm{S}}$ & $\mathrm{R}_{\mathrm{L}}$ & $P_{L}$ & $\mathrm{R}_{\mathrm{S}}$ & $\mathrm{P}_{\mathrm{S}}$ \\
\hline Bosmina $\mathrm{CL}$ & 0 & 0.59 & - & - & 0 & 0.59 & - & - & 0.04 & 0.30 & 0.11 & 0.04 & 0.14 & 0.02 & 0.14 & 0.02 \\
\hline Bosmina $\mathrm{ML}$ & 0 & 0.62 & - & - & 0.05 & 0.18 & - & - & 0.03 & 0.42 & - & - & 0.18 & 0.01 & 0.18 & 0.01 \\
\hline Bosmina AL & 0 & 0.47 & - & - & 0 & 0.74 & - & - & 0 & 0.81 & - & - & 0.17 & 0.03 & 0.26 & 0.04 \\
\hline Eubosmina $\mathrm{AL}$ & 0.06 & 0.18 & - & - & 0.01 & 0.52 & - & - & 0 & 0.52 & - & - & 0.44 & 0.001 & 0.44 & 0.001 \\
\hline D.ambigua $\mathrm{PL}$ & 0 & 0.23 & - & - & 0 & 0.30 & 0.27 & 0.01 & 0.03 & 0.78 & - & - & 0.04 & 0.19 & - & - \\
\hline D.pulex PL & 0.1 & 0.17 & - & - & 0.08 & 0.78 & & - & 0 & 0.78 & - & - & 0.02 & 0.51 & - & - \\
\hline Comm. index & 0 & 0.67 & - & - & 0.02 & 0.36 & - & - & 0.01 & 0.55 & - & - & 0.12 & 0.02 & 0.35 & 0.01 \\
\hline
\end{tabular}
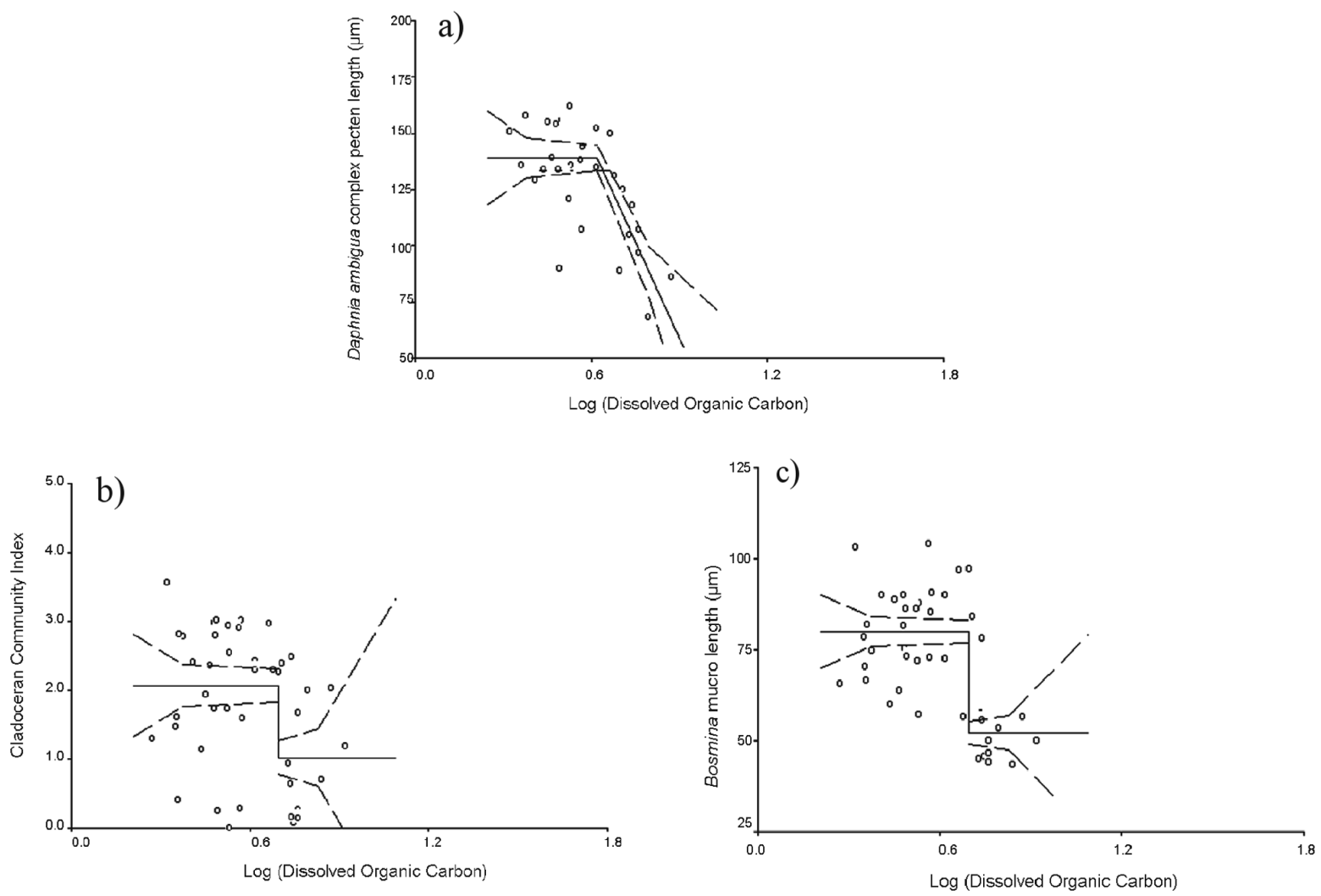

Fig. 4. Graph showing a) a Type-3 relationship between $D$. ambigua complex pecten length and logDOC; b) a Type-5 relationship between the cladoceran community index and $\log$ DOC; c) a Type- 5 relationship between Bosmina mucro length and logDOC. The $90 \%$ confidence belts are shown. 
function explained significantly more variation in size structure $\left(R^{2}=0.52\right.$; Tab. 2a), suggesting that at levels greater than $\sim 5 \mathrm{mg} \mathrm{L}^{-1}$, DOC has a considerable, negative impact on size of species in the D. ambigua complex in these lakes. The break-point was also significant for Bosmina mucro length and the community index $(\mathrm{BP}=$ 0.77 or $5.89 \mathrm{mg} \mathrm{L}^{-1}$ DOC for both variables; Tab. 2a), with larger individuals common in lakes with DOC levels below this threshold, and smaller individuals characteristic of lakes with higher DOC levels. The breakpoint determined for Bosmina carapace length was also $5.89 \mathrm{mg} \mathrm{L}^{-1}$ and, while this was not statistically significant (Tab. 2a), it was close enough to the significance level to suggest that DOC may be important in shaping carapace length as well as mucro length.

No significant linear relationships were detected between size means and pH for either Bosmina or Daphnia (Tab. 3a). However, significant segmented regressions were detected for Bosmina carapace length and $D$. ambigua pecten length (Tab. 2a). Both were related to $\mathrm{pH}$ by a step function, with a $\mathrm{pH}$ break-point of 6.12 for Bosmina carapace length (Fig. 5b) and 6.02 for D. ambigua pecten length (Fig. 5a). Mean size was smaller below the break-point compared to mean size in higher $\mathrm{pH}$ lakes. Results suggest that $\mathrm{pH}$ negatively affects cladoceran size when it falls below a threshold value of 6.0-6.12.

Lake calcium levels were unrelated to size variables by either linear or segmented regressions (Tab. 3a), suggesting $\mathrm{Ca}$ is unimportant in structuring cladoceran size. Our study lakes, however, displayed only a narrow $\mathrm{Ca}$ gradient of 1.0-3.9 $\mathrm{mg} \mathrm{L}^{-1}$.

Chaoborus density indicated no relationship to cladoceran size (Tabs $2 b$ and $3 b$ ). Of the fish presence/absence data, PCA axis 3 displayed significant linear relationships with Bosmina carapace and mucro lengths $\left(\mathrm{R}^{2}=0.14\right.$, and 0.18 , respectively; Fig. $6 \mathrm{c}$, e) and Eubosmina antennule length $\left(\mathrm{R}^{2}=0.44\right.$; Fig. 6d). Significant Type 5 functions were identified for PCA axis 1 with D. ambigua pecten length (Fig. 6a), and PCA axis 3 with Bosmina antennule length (Fig. 6f). Significant Type 4 functions were observed for both PCA axis 2 with Bosmina carapace length (Fig. 6b) and PCA axis 3 with the community index (Fig. 6g).

\section{DISCUSSION}

Zooplankton taxa are key components of aquatic ecosystems, and are sensitive to changes in water quality. Therefore, it is important to understand the controls placed on zooplankton by various limnological variables. This study investigated linear and threshold relationships between pelagic cladoceran size and the limnological variables $\mathrm{pH}, \mathrm{DOC}, \mathrm{TP}, \mathrm{Ca}$, and fish and Chaoborus predation.

Within taxonomic groupings, larger Cladocera were more prevalent in lakes with low TP concentrations,
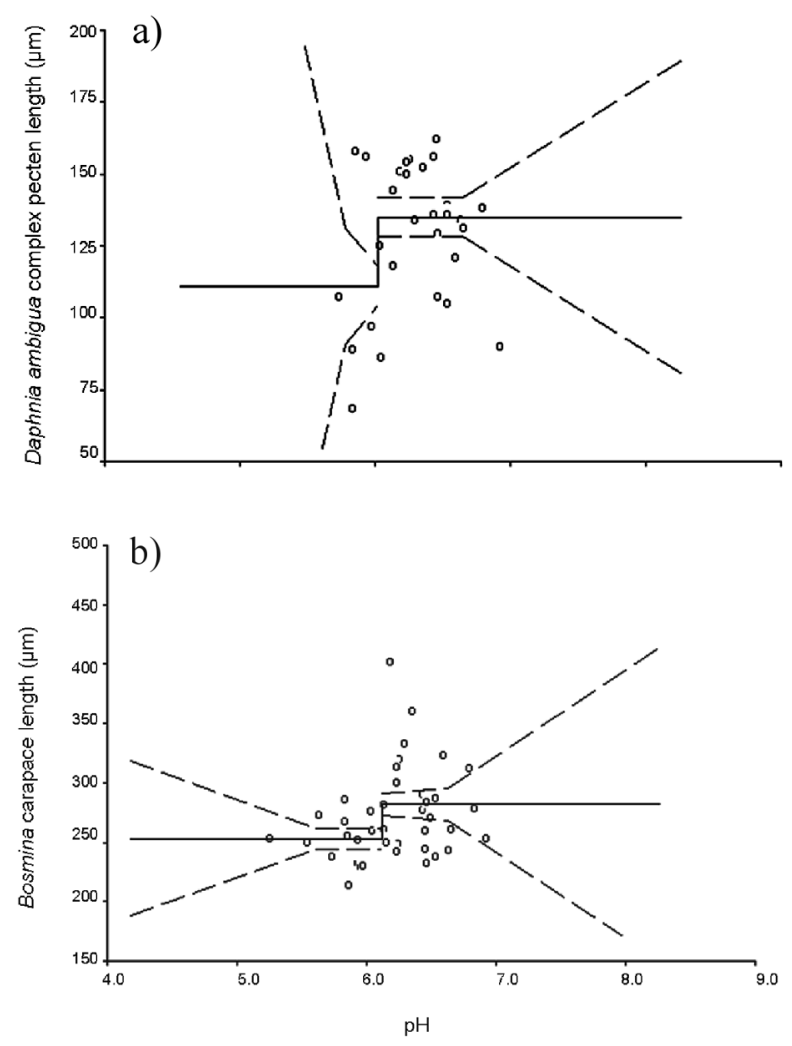

Fig. 5. Graph showing a) a Type-5 relationship between Daphnia ambigua complex pecten length and $\mathrm{pH}$; b) a Type-5 relationship between Bosmina carapace length and $\mathrm{pH}$. The 90 $\%$ confidence belts are shown.

while smaller Cladocera were more common in higher nutrient lakes. This pattern may reflect the ability of larger Cladocera to competitively exclude smaller species when nutrients are limiting, as larger cladocerans have lower limiting thresholds for nutrients (Brooks \& Dodson 1965; Gliwicz 1990). This relationship may also be apparent within the genus level, where a positive correlation between Daphnia body length and filtering rate exists, with larger Daphnia proving to be the more efficient grazers (Burns \& Rigler 1967). When nutrient levels are higher, competition pressures decrease and smaller individuals can proliferate. TP levels are currently declining in many Ontario lakes (Dillon \& Molot 2005) and, consistent with our observations, a trend towards larger mean cladoceran body size with decreasing TP has been observed for Crosson, Dickie, Harp, and Plastic lakes for the time period of 1980-2003 (Yan et al. 2008b).

In addition to TP, DOC has been shown to be important in shaping cladoceran communities in these study lakes (DeSellas et al. 2008; Yan et al. 2008b). DOC can influence cladoceran size in a number of ways. For example, it can impair the visual ability of size-selective predators (Brooks \& Dodson 1965). This suggests that larger Cladocera species should predominate in 

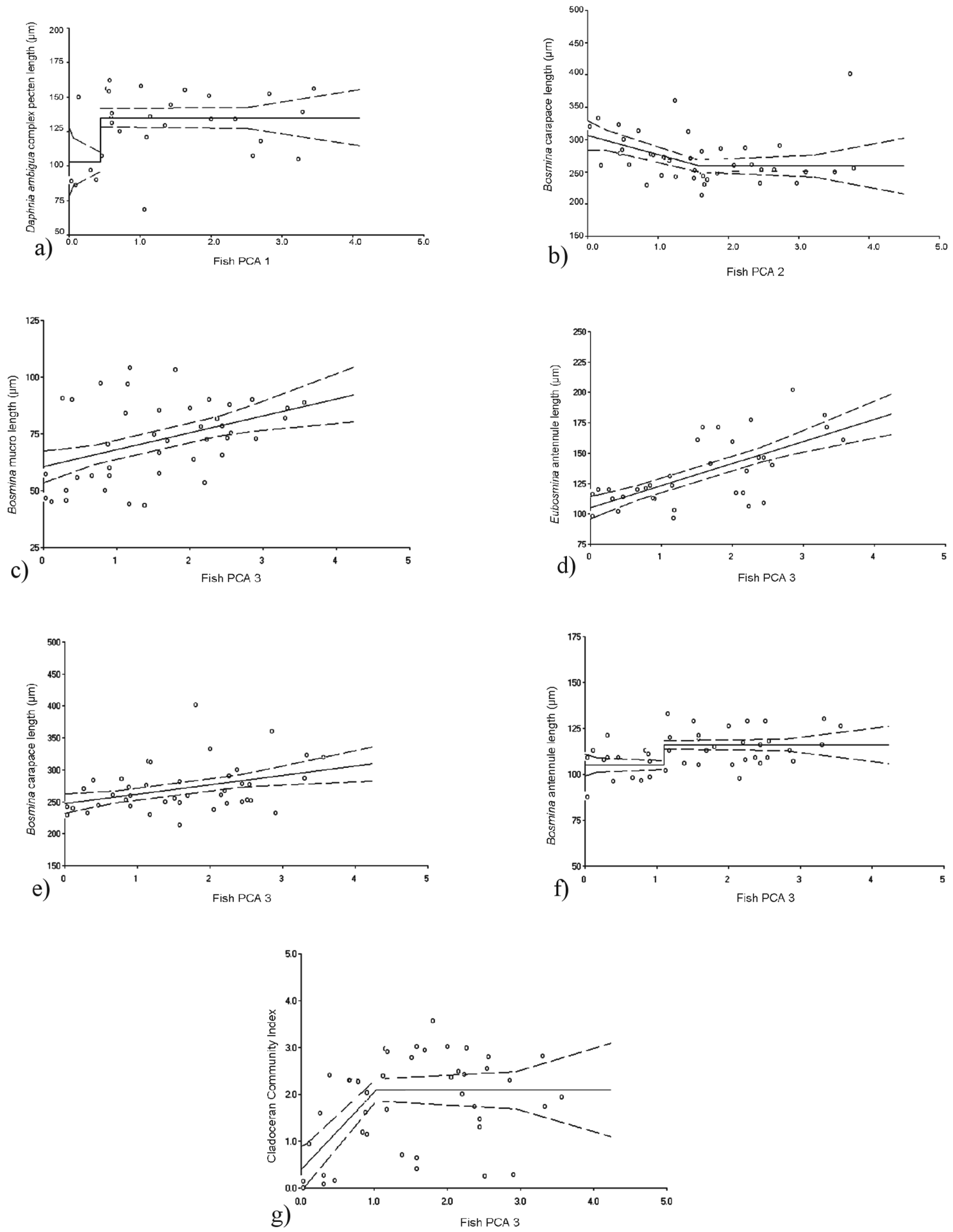

Fig. 6. Graph for fish predation showing a) a Type-5 relationship between $D$. ambigua complex pecten length and Fish PCA 1 ; b) a Type-4 relationship between Bosmina carapace length and Fish PCA 2; c) a linear relationship between Bosmina mucro length and Fish PCA 3; d) a linear relationship between Eubosmina antennule length and Fish PCA 3; e) a linear relationship between Bosmina carapace length and Fish PCA 3; f) a Type-5 relationship between Bosmina antennule length and Fish PCA 3; g) a Type-4 relationship between the cladoceran community index and Fish PCA 3. The 90\% confidence belts are shown. 
high DOC lakes due to decreased fish predation (Yan et al. 2008b). However, our study demonstrated an opposing pattern where, on average, larger cladocerans occurred in lakes with lower DOC concentrations. Cladocera face predation from two main sources: macroinvertebrates and planktivorous fish. Invertebrate predators are limited by gape size, and when they contribute the majority of predation pressure in a lake, it is common to observe larger cladoceran taxa (Nilssen \& Sandoy 1990; Yan et al. 2001). Alternatively, fish predators will actively seek out the largest individuals when visibility is not limited. When fish predation is more important, any factor that decreases visibility should select for increasing cladoceran size within a lake (Brooks \& Dodson 1965). The presence of smaller Cladocera in our high DOC study lakes could suggest a predominance of invertebrate predation in this lake set.

The importance of DOC in controlling UV attenuation in lakes is also well studied (Morris et al. 1995; Williamson et al. 1996; Leech \& Williamson 2000). In lakes with low DOC levels (below 1-2 $\mathrm{mg} \mathrm{L}^{-1}$ ), even small changes in DOC can have large impacts on $1 \%$ UV attenuation depth (Williamson et al. 1996). UV radiation in lakes can be harmful to cladoceran populations (Williamson et al. 1994; Leech \& Williamson 2000); however, in Canadian inland waters, DOC levels were high enough in lakes south of the treeline to prevent extirpation of UV-sensitive Daphnia species (Molot et al. 2004). In our study, the lake with the lowest DOC concentration (Pearceley) still had levels of $1.95 \mathrm{mg} \mathrm{L}^{-1}$, and most other lakes had concentrations higher than $2.5 \mathrm{mg} \mathrm{L}^{-1}$. This suggests that DOC levels in these lakes were high enough to prevent a UV-related cladoceran size response.

In addition, DOC was highly correlated to TP in our lake set $\left(\mathrm{R}^{2}=0.81\right.$; DeSellas et al. 2008), and the size response to the DOC gradient may actually be an artefact of the size-TP relationship. However, the relationship between size and TP was determined to be linear, while size displayed a threshold relationship to DOC. This could suggest that DOC in these lakes had some impact on cladoceran size independent of TP.

Cladoceran community dynamics can also be influenced by lakewater pH (DeSellas et al. 2008). Some zooplankton taxa experience physiological stress under laboratory conditions of declining $\mathrm{pH}$ (Havas 1987). They are also indirectly affected by increased water clarity, metal mobilization, slowed nutrient cycling, and induced changes in trophic food web structure that often occur during acidification (Smol 2008). Many Canadian Shield lakes have been affected by acidification (Neary et al. 1990; Hall \& Smol 1996), resulting in considerable damage to the zooplankton community (Havens et al. 1993). Daphnia taxa are the most sensitive to acidification, while Bosmina longirostris and Leptodiaptomus minutus (a copepod) are often the dominant crustacean zooplankton in acid lakes follo- wing release from competition with Daphnia (Havens et al. 1993).

Studies have assigned a critical $\mathrm{pH}$ value for cladoceran species richness at 5.0-5.5, with recovery from acidification stress occurring at $\mathrm{pH} 6.0$ (Nilssen \& Sandoy 1990; Korhola \& Rautio 2001). Daphnia taxa are rare in lakes with $\mathrm{pH}<6.0$ (Keller et al. 1990; Havens et al. 1993). A study specific to south-central Ontario identified pH 6.0 as the threshold for maximal community change when considering species richness and abundance (Holt et al. 2003). Similarly, we found a significant $\mathrm{pH}$ threshold of approximately 6.0 , with larger mean cladoceran size above this threshold. Field experiments have also shown smaller Bosmina in acid conditions relative to Bosmina in neutral lakes (Locke \& Sprules 2000). This could be due to direct physiological stress placed on Bosmina through increased metal cycling and acidity, or it could also be a response to a shift in algal assemblages from larger to smaller species (Cattaneo et al. 1998). Few lakes in this study had a pH lower than 6.0, and an even stronger size-pH link might therefore be found in a study comparing acidified to neutral lakes (Yan et al. 1996). The rare incidence of Daphnia in low pH lakes suggests that Bosmina size trends are the best indicators of $\mathrm{pH}$ in these study lakes.

The link between cladoceran size and $\mathrm{pH}$ can be complicated by changes in trophic structure related to acidification. The $\mathrm{pH}$ of a lake can affect the abundance of cladoceran predators, which can in turn can affect cladoceran size distribution. In acid lakes, predation by acid-tolerant Chaoborus may become more important (Yan et al. 1991). As Chaoborus are gape-limited predators, declining $\mathrm{pH}$ may select for larger Bosmina individuals. The role of acidification in altering food web structure should be considered when interpreting cladoceran size-pH data.

Lake $\mathrm{Ca}$ levels present an additional potential constraint on mean Cladocera size. Ca is an essential structural component of cladoceran carapaces (Stevenson 1985), and has been shown to be important in influencing sedimentary cladoceran assemblages in our study lakes (DeSellas et al. 2008). Cladoceran species differ in their Ca requirements, with Daphnia having the highest $\mathrm{Ca}$ requirement (as much as 20x) of all Cladocera (Jeziorski \& Yan 2006). The high Ca requirements of Daphnia suggests that increased $\mathrm{Ca}$ concentrations in lakes would allow larger daphniid species with high $\mathrm{Ca}$ demands (such as D. pulex, whose minimum Ca requirement is $1.5 \mathrm{mg} \mathrm{L}^{-1}$, Ashforth \& Yan 2008) to proliferate where present. Thus, a Ca gradient could be important in determining the size structure of daphniids, in addition to cladoceran community composition. However, no link was observed between $\mathrm{Ca}$ and any size variable in this study. This is not surprising, as only three of our study lakes (Cradle, Maggie, and Pearceley) had Ca levels $<1.5 \mathrm{mg} \mathrm{L}^{-1}$, which is the current suggested threshold for growth and survival of Daphnia (Ashforth \& 
Yan, 2008). An analysis of cladoceran size across a larger calcium gradient may reveal trends that are more significant.

The fish presence/absence data used in this study revealed some significant correlations with cladoceran size along the third PCA axis, suggesting that certain fish species loading onto this PCA axis are influencing cladoceran size structure. No significant trends were observed with size and Chaoborus density. Chaoborus density and fish presence/absence data, however, are likely not adequate measures to use when attempting to determine the impacts of predation on cladoceran community dynamics in south-central Ontario (DeSellas et al. 2008). Unfortunately, long-term, detailed records of planktivorous fish and macroinvertebrate predators in our lakes were unavailable at the time of this study, and it was difficult to determine at what level of the food chain they were feeding at in each lake. Strong correlations between zooplankton size and fish community structure (Mills \& Schiavone 1982), predator-to-panfish ratio (Mills et al. 1987), age structure of fish (Mills et al. 1987), and mean panfish length (Mills et al. 1987) have previously been identified, and may be better measures of fish predation. The low $\mathrm{R}^{2}$ values observed in this study suggest that some control on cladoceran size was missing in this analysis, and gaps in the predation data could account for at least some of the unexplained size variability. Previous research in this region, however, has suggested that fish predation may have minimal influence on cladoceran community assemblage and size structure (DeSellas et al. 2008; Yan et al. 2008b).

Significantly, no relationship was observed between limnological variables and the Daphnia pulex complex. Each Daphnia complex contains species with varying sizes and environmental preferences. The Daphnia ambigua complex contains two moderately large species (D. dubia, D. mendotae) and two smaller ones (D. ambigua, D. longiremis), while the Daphnia pulex complex contains four species that are all relatively large. The size trends seen in the D. ambigua complex are likely the result of species replacement, with larger species becoming more common under certain environmental conditions (or vice versa). Species replacement in the $D$. pulex complex is likely also occurring in response to changing limnological conditions; however, because there is less size variability between these species, no size trends in the surface sediments were observed.

Investigations into the dynamics of aquatic ecology will be greatly enriched by an increased understanding of water quality controls on zooplankton taxonomic composition and size spectra. Some size measures are more sensitive than others in detecting relationships with limnological variables. These include Bosmina mucro and carapace lengths, and D. ambigua complex pecten lengths. The calculated community index displayed some significant, yet weaker correlations with limnological variables, suggesting that further paleolimnological studies on cla- doceran size should focus on individual measures, with emphasis on those measures that were are most sensitive. A similar investigation is underway to evaluate the size of Cladocera in pre-industrial sediments from the same cores used in this study. This will permit comparisons between present-day and pre-industrial assemblages to determine if cladoceran size-structure has changed in response to industrialization or other environmental stressors, such as climate change and Bythotrephes invasion. The predictability of size responses to changes in a lake's environment has the potential to be an effective paleolimnological tool, as size-based approaches could serve as a complement to taxonomic approaches in effectively reconstructing the history of a lake.

\section{CONCLUSIONS}

We examined the influence of abiotic and biotic factors on the mean body size of pelagic cladoceran body parts in the surface sediments of Precambrian Shield lakes and found that cladoceran size structure was related to changes in limnological variables. Specifically, $\mathrm{TP}, \mathrm{pH}$, and potentially DOC were highlighted as the main factors related to mean body size in our 42 southcentral Ontario study lakes. Larger bosminiids and daphniids were more common in lakes with low TP, low DOC, and circumneutral pH. Detailed Chaoborus and planktivorous fish abundance data were unavailable at the time of this study and, as a result, it was difficult to determine the influence of predation on cladoceran size structure in our lakes. Some significant trends observed between fish PCA axis 3 and Bosmina size suggests fish predation is potentially important. The relationships we observed between environmental variables and cladoceran fossil size suggest that size-based paleolimnological approaches could complement taxonomic approaches in effectively reconstructing the history of Precambrian Shield lakes.

\section{ACKNOWLEDGEMENTS}

We thank Michelle Palmer and Dr. Norman Yan at York University, as well as Ron Ingram of the Ontario Ministry of the Environment (Dorset Ontario), for providing water chemistry data. We also thank the Ontario Ministry of Natural Resources for supplying fish data, and the Ontario Ministry of the Environment for providing Chaoborus data. Thanks to Carole Chueng, Bev Clark, Adam Jeziorski, Michelle Palmer, and Ron Ingram for their participation in the field work, Dr. Jon Sweetman for his ideas and input, and to Dr. Kathleen Rühland and Dr. Bob Montgomerie of Queen's University for their assistance in the statistical analyses. This project is funded by an Ontario Ministry of the Environment Best in Science Grant, and NSERC grants to JPS. 


\section{REFERENCES}

Amsinck, S.L., A. Strzelczak, R. Bjerring, F. Landkildehus, T.L. Lauridsen, K. Christoffersen \& E. Jeppesen. 2006. Lake depth rather than fish planktivory determines cladoceran community structure in Faroese lakes - evidence from contemporary data and sediments. Fresh. Biol., 51: 2124-2142.

Ashforth, D. \& N.D. Yan. 2008. The interactive effects of calcium concentration decline and temperature increase on the survival and reproduction of Daphnia pulex at high and low food concentrations. Limnol. Oceanogr., 53: 420-432.

Bos, D.G. \& B.F. Cumming. 2003. Sedimentary Cladocera remains and their relationship to nutrients and other limnological variables in 53 lakes from British Columbia, Canada. Can. J. Fish. Aquat. Sci., 60: 1177-1189.

Bos, D.G., B.F. Cumming \& J.P. Smol. 1999. Cladocera and Anostraca from the Interior Plateau of British Colombia, Canada, as paleolimnological indicators of salinity and lake level. Hydrobiologia, 392: 129-141.

Brooks, J.L. \& S.I. Dodson. 1965. Predation, body size, and composition of plankton. Science, 150: 28-35.

Burns, C.W. 1968. The relationship between body size of filterfeeding Cladocera and the maximum size of the particle ingested. Limnol. Oceanogr., 13: 675-678.

Burns, C.W. \& F.H. Rigler. 1967. Comparison of filtering rates of Daphnia rosea in lake water and in suspensions of yeast. Limnol. Oceanogr., 12: 492-502.

Cattaneo, A., A. Asioli, P. Comoli \& M. Manca. 1998. Organism's response in a chronically polluted lake supports hypothesized link between stress and size. Limnol. Oceanogr., 43: 1938-1943.

Chapman, L.J. \& D.F. Putnam. 1984. The Physiography of Southern Ontario. 2. Ontario Geological Survey, Sudbury, Ontario.

Cosby, B.J., G.M. Hornberger, J.N. Galloway \& R.F. Wright. 1985. Time scales of catchment acidification. Environ. Sci. Technol., 19: 1144-1149.

Davidson, T.A., C.D. Sayer, M.R. Perrow, M. Bramm \& E. Jeppesen. 2006. Are the controls of species composition similar for contemporary and sub-fossil cladoceran assemblages? A study of 39 shallow lakes of contrasting trophic status. J. Paleolimnol., 38: 117-134.

DeSellas, A.M., A.M. Paterson, J.N. Sweetman \& J.P. Smol. 2008. Cladocera assemblages from the surface sediments of south-central Ontario (Canada) lakes and their relationships to measured environmental variables. Hydrobiologia, 600: 105-119.

Dillon, P.J. \& L.A. Molot. 2005. Long-term trends in catchment export and lake retention of dissolved organic carbon, dissolved organic nitrogen, total iron and total phosphorus: The Dorset, Ontario study, 1978-1998. J. Geophys. Res., 110, G01002, doi:10.1029/2004JG000003.

Driscoll, C.T., G.B. Lawrence, A.J. Bulger, T.J. Butler, C.S. Cronan, C. Eagar, K.F. Lambert, G.E. Likens, J.L. Stoddard \& K.C. Weathers. 2001. Acidic deposition in the northeastern United States: sources and inputs, ecosystem effects, and management strategies. BioScience, 51: 180-198.

Gamble, A.E., R. Lloyd, J. Aiken, O.E. Johannsson \& E.L. Mills. 2006. Using zooplankton biomass size spectra to assess ecological change in a well-studied freshwater lake ecosystem: Oneida Lake, New York. Can. J. Fish. Aquat. Sci., 63: 2687-2699.

Glew, J. 1988. A portable extruding device for close interval sectioning of unconsolidated core samples. J. Paleolimnol., 1: $235-239$.

Glew, J. 1989. A new trigger mechanism for sediment samplers. J. Paleolimnol., 2: 241-243.

Glew, J. 1991. Miniature gravity corer for recovering short sediment cores. J. Paleolimnol., 5: 285-287.
Gliwicz, Z.M. 1990. Food thresholds and body size in cladocerans. Nature, 343: 638-640.

Hall, R.I. \& J.P. Smol. 1996. Paleolimnological assessment of long-term water-quality changes in south-central Ontario lakes affected by cottage development and acidification. Can. J. Fish. Aquat. Sci., 53: 1-17.

Havas, M. 1987. Does haemoglobin enhance the acid-tolerance of Daphnia? Annales de la Societe Royale Zoologique de Belgique, 117:151-164.

Havens, K.E., N.D. Yan \& W. Keller. 1993. Lake acidification: effects on crustacean zooplankton populations. Environ. Sci. Technol., 27: 1621-1624.

Holt, C.A., N.D. Yan \& K.M. Somers. 2003. pH 6 as the threshold to use in critical load modeling for zooplankton community change with acidification in lakes of south-central Ontario: accounting for morphometry and geography. Can J. Fish. Aquat. Sci., 60: 151-158.

Hrbáček, J. 1969. On the possibility of estimating predation pressure and nutrition level of populations of Daphnia (Crust., Cladoc.) from their remains in sediments. Mitt. Internat. Verein. Limnol., 17: 269-274.

Jeziorski, A. \& N.D. Yan. 2006. Species identity and aqueous calcium concentrations as determinants of calcium concentrations of freshwater crustacean zooplankton. Can. J. Fish. Aquat. Sci., 63: 1007-1013.

Keller, W., S.S. Dixit \& J. Heneberry. 2001. Calcium declines in northeastern Ontario lakes. Can. J. Fish. Aquat. Sci., 58: 2011-2020.

Keller, W., N.D. Yan, K.E. Holtze \& J.R. Pitblado. 1990. Inferred effects of lake acidification on Daphnia galeata mendotae. Environ. Sci. Technol., 24: 1259-1261.

Korhola, A. \& M. Rautio. 2001. Cladocera and other brachiopod crustaceans. In: J.P. Smol, H.J.B. Birks \& W.M. Last (Eds), Tracking Environmental Change Using Lake Sediments 4: Zoological Indicators. Kluwer Academic Publishers, Dordrecht, The Netherlands: 5-41.

Korhola, A., M. Tikkanen \& J. Weckström. 2005. Quantification of Holocene lake-level changes in Finnish Lapland using a cladocera-lake depth transfer model. $J$. Paleolimnol., 34: 175-190.

Leech, D.M. \& C.E. Williamson. 2000. Is tolerance to UV radiation in zooplankton related to body size, taxon, or lake transparency? Ecological Applications, 10: 1530-1540.

Locke, A. \& W.G. Sprules. 2000. Effects of acidic pH and phytoplankton on survival and condition of Bosmina longirostris and Daphnia pulex. Hydrobiologia, 437: 187-196.

Manca, M. \& P. Comoli. 1996. Reconstructing population size structure in Cladocera by measuring their body remains. Mem. Ist. Ital. Idrobiol., 54: 61-68.

Manca, M. \& P. Comoli. 2004. Reconstructing long-term changes in Daphnia's body size from subfossil remains in sediments of a small lake in the Himalayas. J. Paleolimmol., 32: 95-107.

Manca, M., B. Torretta, P. Comoli, S.L. Amsinck \& E. Jeppesen. 2007. Major changes in trophic dynamics in large, deep, sub-alpine Lake Maggiore from 1940s to 2002: a high resolution comparative palaeo-neolimnological study. Fresh. Biol., 52: 2256-2269.

Mills, E.L. \& A. Schiavone. 1982. Evaluation of fish communities through assessment of zooplankton populations and measures of lake productivity. N. Am. J. Fish. Manag., 2: 14-27.

Mills, E.L., D.M. Green \& A. Schiavone. 1987. Use of zooplankton size to assess the community structure of fish populations in freshwater lakes. N. Am. J. Fish. Manag., 7: 369-378.

Molot, L.A., W. Keller, O.R. Leavitt, R.D. Robarts, M.J. Waiser, M.T. Arts, T.A. Clair, R. Pienitz, N.D. Yan, D.K. McNicol, Y.T. Prairie, P.J. Dillon, M. Macrae, R. Bello, R.N. Nordin, P.J. Curtis, J.P. Smol \& M.S.V. Douglas. 
2004. Risk analysis of dissolved organic matter-mediated ultraviolet B exposure in Canadian inland waters. Can. J. Fish. Aquat. Sci., 61: 2511-2521.

Moore, M.V., C.L. Folt \& R.S. Stemberger. 1996. Consequences of elevated temperatures for zooplankton assemblages in temperate lakes. Arch. Hydrobiol., 135: 289-319.

Morris, D.P., H. Zagarese, C.E. Williamson, E.G. Balseiro, B.R. Hargreaves, B. Modenutti, R. Moeller \& C. Queimalinos. 1995. The attenuation of solar UV radiation in lakes and the role of dissolved organic carbon. Limnol. Oceanogr., 40: 1381-1391.

Neary, B.P., P.J. Dillon, J.R. Munro \& B.J. Clark. 1990. The acidification of Ontario lakes: an assessment of their sensitivity and current status with respect to biological damage. Ontario Ministry of the Environment, Dorset, Ontario.

Nilssen, J.P. \& S. Sandoy. 1990. Recent lake acidification and cladoceran dynamics: surface sediment and core analysis from lakes in Norway, Scotland and Sweden. Phil. Trans. R. Soc. Lond., 327: 299-309.

Oosterbaan, R.J., D.P. Sharma, K.N Singh \& K.V.G.K. Rao. 1990. Crop production and soil salinity: evaluation of field data from India by segmented linear regression with breakpoint. In: Proc. Symp. Land Drainage for Salinity Control in Arid and Semi-Arid Regions III. Drainage Research Institute, Cairo: 373-383.

Paterson, A.M., B.F. Cumming, J.P Smol \& R.I. Hall. 2004. Marked recent increases of colonial scaled chrysophytes in boreal lakes: implications for the management of taste and odour events. Fresh. Biol., 49: 199-207.

Schindler, D.W. 2001. The cumulative effects of climate warming and other human stresses on Canadian freshwaters in the new millennium. Can. J. Fish. Aquat. Sci., 58: 18-29.

Smol, J.P. 2008. Pollution of Lakes and Rivers, a Paleoenvironmental Perspective. $2^{\text {nd }}$ ed. Blackwell, Oxford.

Stevenson, J.R. 1985. Dynamics of the integument. In: D.E. Bliss \& L.H. Mantel (Eds), The Biology of Crustacea 9: Integument, pigments, and hormonal processes. Academic Press, New York: 1-42.

Sweetman, J.N. \& B.P. Finney. 2003. Differential responses of zooplankton populations (Bosmina longirostris) to fish predation and nutrient loading in an introduced and natural sockeye salmon nursery lake on Kodiak Island, Alaska, USA. J. Paleolimnol., 30: 183-193.

Taylor, D.J., C.R. Ishikane \& R.A. Haney. 2002. The systematics of Holarctic Bosminids and a revision that reconciles molecular and morphological evolution. Limnol. Oceanogr., 47: 1486-1495.

Received: January 2008

Accepted: April 2008
Watmough, S.A., J. Aherne \& P.J. Dillon. 2003. Potential impacts of forest harvesting on lake chemistry in southcentral Ontario at current levels of acid deposition. Can. J. Fish. Aquat. Sci., 60: 1095-1103.

Williamson, C.E., H.E. Zagarese, P.C. Schulze, B.R. Hargreaves \& J. Seva. 1994. The impact of short-term exposure to UV-B radiation on zooplankton communities in north temperate lakes. J. Plankton Res., 16: 205-218.

Williamson, C.E., R.S. Stemberger, D.P. Morris, T.M. Frost \& S.G. Paulsen. 1996. Ultraviolet radiation in North American lakes: attenuation estimates from DOC measurements and implications for plankton communities. Limnol. Oceanogr., 41: 1024-1034.

Witty, L.M. 2004. Practical guide to identifying freshwater crustacean zooplankton. Cooperative Freshwater Ecology Unit, Department of Biology, Laurentian University.

Yan, N.D. \& T.W. Pawson. 1997. Changes in the crustacean zooplankton community of Harp Lake, Canada, following invasion by Bythotrephes cederstroemi. Fresh. Biol., 37: 409-425.

Yan, N.D., W. Keller, H.J. MacIsaac \& L.J. McEachern. 1991. Regulation of zooplankton community structure of an acidified lake by Chaoborus. Ecol. Appl., 1: 52-65.

Yan, N.D., W. Keller, K.M. Somers, T.W. Pawson \& R.E. Girard. 1996. Recovery of crustacean zooplankton communities from acid and metal contamination: comparing manipulated and reference lakes. Can. J. Fish. Aquat. Sci., 53: 1301-1327.

Yan, N.D., A. Blukacz, W.G. Sprules, P.K. Kindy, D. Hackett, R.E. Girard \& B.J. Clark. 2001. Changes in zooplankton and the phenology of the spiny water flea, Bythotrephes, following its invasion of Harp Lake, Ontario, Canada. Can. J. Fish. Aquat. Sci., 58: 2341-2350.

Yan, N.D., A.M. Paterson, K.M. Somers \& W.A. Scheider. 2008a. An introduction to the Dorset special issue: transforming understanding of the factors that regulate aquatic ecosystems on the southern Canadian Shield. Ca. J. Fish. Aquat. Sci., 65: 781-785.

Yan, N.D., K.M. Somers, R.E. Girard, A.M. Paterson, C.W. Ramcharan, J.A. Rusak, R. Ingram, G.E. Morgan \& J.M. Gunn. 2008b. Long-term changes in crustacean zooplankton communities of Dorset, Ontario lakes: the probable interactive effects of changes in $\mathrm{pH}, \mathrm{TP}$, dissolved organic carbon, and predators. Can. J. Fish. Aquat. Sci, 65: 862877. 